
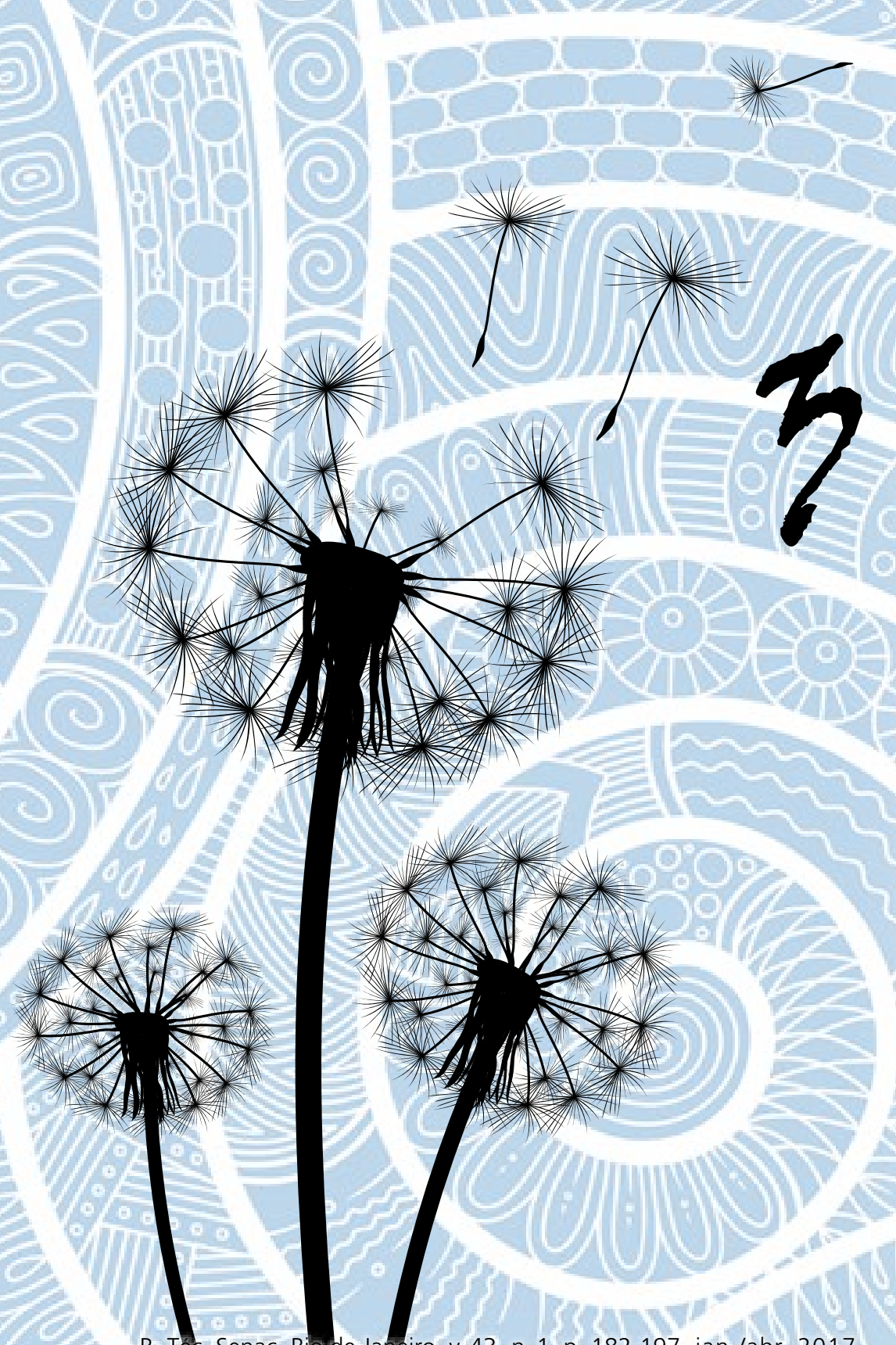

B. Téc. Senac, Rio de Janeiro, v. 43, n. 1, p. 182-197, jan./abr. 2017.
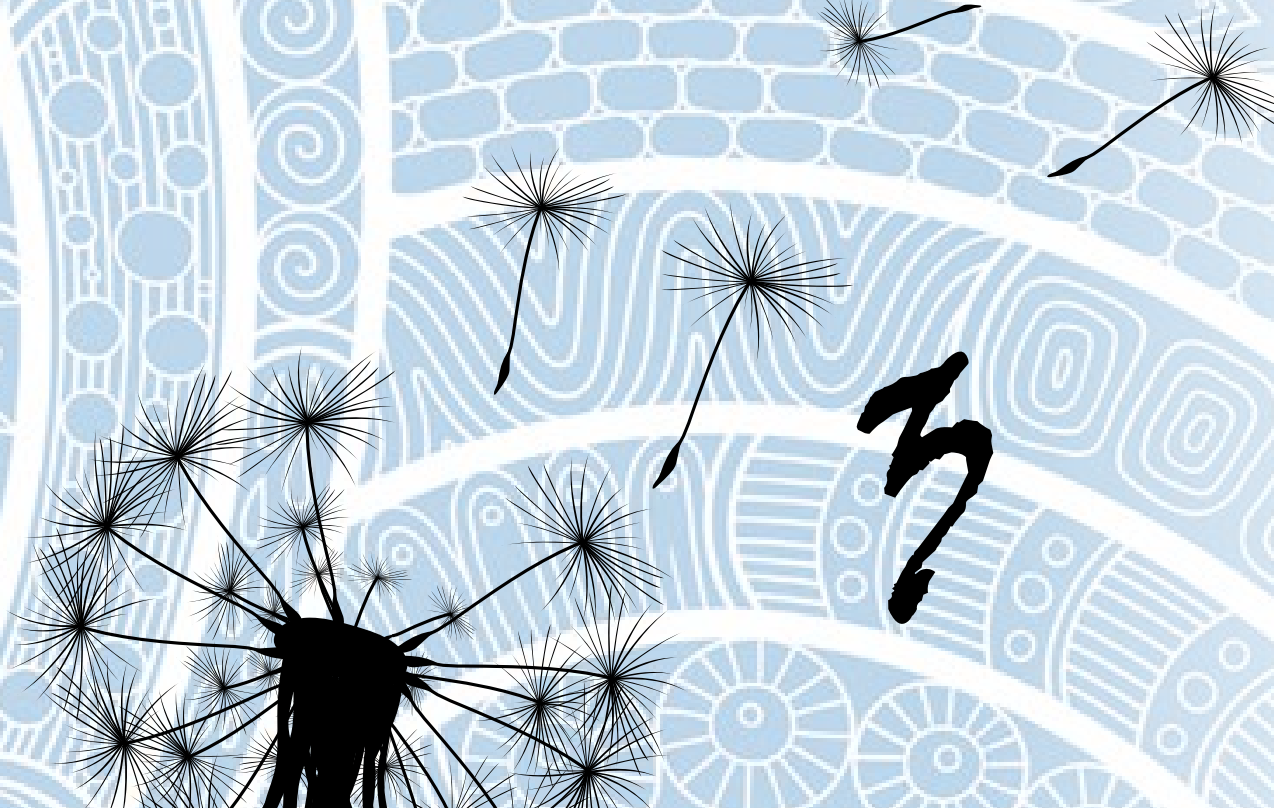


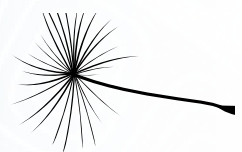

\title{
PESQUISA E ENSINO \\ EM ADMINISTRAÇÃO E \\ CONTABILIDADE
} RESEARCH AND TEACHING IN BUSINESS MANAGEMENT
AND ACCOUNTING

\section{INVESTIGACIÓN Y ENSEÑANZA SOBRE \\ ADMINISTRACIÓN Y CONTABILIDAD}

\author{
Rodrigo Souza da Costa* \\ Alboni Marisa Dudeque Pianovski Vieira**
}

*Pesquisador do Programa de Pós-graduação em Administração (PPAD) da Pontifícia Universidade Católica do Paraná (PUC - PR). Mestre em Administração, doutorando em Administração. Curitiba, Paraná, Brasil. E-mail: mscrodrigodacosta@gmail. com

**Professora do Programa de Pós-graduação em Educação (Mestrado e Doutorado) da PUC - PR. Mestre e Doutora em Educação. Curitiba, Paraná, Brasil. E-mail: alboni. vieira@pucpr.br; alboni@ alboni.com

Recebido para publicação em: 3.5.2016

Aprovado em: 18.1.2017

\section{Resumo}

O objetivo do artigo é descrever o perfil das pesquisas da área de Ensino e Pesquisa em Administração e Contabilidade, nos artigos publicados nos anais do Encontro Anual da Associação Nacional dos Programas de Pós-graduação em Administração, período 2001-2014. Optou-se pela realização de um estudo bibliométrico, que possibilita a geração de índices e análises estatísticas da produção científica. Os resultados demonstram que a maioria dos artigos investigados aborda temas relativos ao ensino e aprendizagem em Administração e Contabilidade, com forte tendência a trabalhar "casos de ensino".

Palavras-chave: Bibliometria. Pesquisa e ensino. Análise evolutiva. Administração. Contabilidade.

\section{Abstract}

The objective of this article is to describe the research profile in field of Education and Research in Business Management and Accounting, in articles published in the proceedings of the Annual Meeting of the National Association of Graduate Programs in Management (Encontro Anual da Associação Nacional dos Programas de Pós-graduação em Administração), in 2001-2014. It was opted to perform a bibliometric study, which enables the generation of indexes and statistical analysis of scientific production. The results show that most of the investigated articles cover topics related to teaching and learning in Business Administration and Accounting, with a strong tendency to explore "teaching cases". 
Keywords: Bibliometry. Research and teaching. Evolutionary analysis. Management. Accounting.

\section{Resumen}

El objetivo de este artículo es describir el perfil de las investigaciones del área de Enseñanza e Investigación sobre Administración y Contabilidad, tomando como objeto los artículos publicados en los anales del Encuentro Anual de la Associação Nacional dos Programas de Pós-graduação em Administração (ANPAD), en el periodo 2001-2014. Se optó por efectuar un estudio bibliométrico, el cual posibilita la generación de índices y la realización de análisis estadísticos de la producción científica. Los resultados demuestran que la mayoría de los artículos investigados aborda temas relativos a la enseñanza y aprendizaje en Administración y Contabilidad, con fuerte tendencia a trabajar "casos didácticos".

Palabras clave: Bibliometría. Investigación y enseñanza. Análisis evolutivo. Administración. Contabilidad.

\section{Introdução}

A realização de pesquisas apresenta importância significativa na atividade das universidades e de seu corpo docente. Além disso, a publicação dessas pesquisas tem como objetivo essencial o desenvolvimento e a disseminação do conhecimento para além das fronteiras da universidade, chegando à sociedade pela publicação em periódicos e anais de eventos e fóruns. $\mathrm{O}$ número de pesquisas no campo da Administração apresentou, nos últimos anos, uma crescente quantidade de publicações (ROSSONI et al., 2007). Devido a isso, os estudos que analisaram essa evolução também cresceram substancialmente na área. Entre esses estudos, o trabalho de Machado-da-Silva, Cunha e Amboni (1990) apresenta, em seus resultados, que há uma deficiência metodológica na produção científica da área de Organizações, dessa forma, chamando atenção dos pesquisadores para novas abordagens teóricas e metodológicas que poderiam auxiliar o desenvolvimento das pesquisas. Nesse sentido, fica ressaltada a importância do mapeamento da produção científica e de que este processo se inicia verificando as principais características da área analisada (HID; NASCIMENTO; OLIVEIRA, 2012).

Mesmo com o crescente número de trabalhos que acadêmicos e estudantes produzem, ainda não são numerosos aqueles que fazem a análise da produção científica em Administração no contexto nacional (GALLON et al., 
2008). Do mesmo modo, ainda é necessário se analisar algumas características que favorecem a qualidade das pesquisas na área de Administração, sobretudo quando os trabalhos tratam de Ensino e Pesquisa em Administração e Contabilidade, pois se trata de uma área de investigação que deve propiciar aos docentes e pesquisadores novos elementos a serem propostos, discutidos e aplicados. Logo, fica evidente a necessidade de uma reflexão sistemática sobre a construção do conhecimento produzido nos periódicos e eventos brasileiros, no sentido de se questionar quais são as discussões teóricas que ocorrem e quais métodos e teorias vêm sendo aplicados nas pesquisas nacionais, buscando explicar como estão sendo desenvolvidos os estudos nessa área temática.

Tendo em vista o exposto e a necessidade de constantemente se rever alguns conceitos dentro do campo de conhecimento, o objetivo deste trabalho é descrever o perfil das pesquisas e a evolução da área de Ensino e Pesquisa em Administração e Contabilidade (EPQ) nos artigos publicados nos anais do Encontro Anual da Associação Nacional dos Programas de Pós-graduação em Administração (Enanpad), no período de 2001-2014. Para atender este objetivo, dentro dos temas de interesse da área, foram analisados o perfil das pesquisas e a evolução do tema nos artigos selecionados para publicação durante o período. Além disso, será exposta a participação que cada uma das diversas áreas de interesse do tema representa, o crescimento e o declínio de alguns tipos de estudos e, consequentemente, quais as maiores preocupações dos autores que publicam no mencionado evento.

Optou-se aqui pelo estudo bibliométrico, técnica de pesquisa que permite a geração de índices e análises estatísticas, possibilitando que seja elaborada uma avaliação da produção científica de um país, das instituições e dos cientistas (MACIAS-CHAPULA, 1998). A bibliometria consiste em um conjunto de leis intrinsecamente relacionadas à Ciência da Informação, que se desenvolveu tendo como base a Teoria da Informação, mas que, no entanto, apresenta um arcabouço teórico próprio (BRAGA, 1973). Este tipo de pesquisa se diferencia principalmente no que se refere ao seu objeto de estudo (VANTI, 2002) pois os estudos bibliométricos voltam-se para análise de livros, documentos e periódicos, gerando variáveis observáveis e abordagens diferenciadas para a análise do tema em questão (TEIXEIRA; IWAMOTO; MEDEIROS, 2013).

Com base nesses pressupostos, este artigo está organizado da seguinte forma: primeiramente, tem-se a introdução e, na sequência, será constituído o referencial teórico tratando dos conceitos essenciais da bibliometria e os procedimentos metodológicos utilizados na pesquisa. Ao final, serão expostos, analisados e discutidos os resultados, com as considerações derivadas das interpretações e sua corroboração, tendo como base as referências discutidas. 


\section{Conceitos e elementos da análise bibliométrica}

Pode-se considerar, de forma geral, que a bibliometria está relacionada às áreas de Biblioteconomia e Ciência da Informação, e se utiliza da aplicação de métodos estatísticos e matemáticos para analisar e construir indicadores sobre a evolução da informação científica de determinadas áreas (FONSECA, 1986). O significado de bibliometria abrange todos aqueles estudos que buscam quantificar os processos de comunicação escrita. Em relação à sua abrangência, os estudos bibliométricos são interdisciplinares ou multidisciplinares e podem ser aplicados em todas as áreas do conhecimento. Além disso, apresentam relações com as áreas de Cientometria, Informetria, Webometria, Patentometria, entre outras (PRITCHARD, 1969).

As pesquisas bibliométricas tratam de estudos específicos para a mensuração dos índices de produção acadêmica. O método de pesquisa surgiu com as análises de medição da produtividade científica, tendo como fundamento a lei de dispersão do conhecimento científico, distribuição e frequência das palavras (LOTKA, 1926; BRADFORD, 1934; ZIPF, 1949). Partindo dessas premissas, pode-se inferir que as pesquisas bibliométricas baseiam-se em três leis clássicas, conforme segue:

I. Lei de Lotka: desenvolvida com a mensuração da produção científica do Chemical Abstracts, que se trata de um grupo de pesquisas químicas nos Estados Unidos, entre 1909 e 1916. De acordo com essa Lei, a maior parte das pesquisas científicas é produzida por um número pequeno de autores, enquanto a maior parte dos autores representam uma parcela pequena de toda a produção científica.

II. Lei de Bradford: divide os periódicos de uma área em três partes, cada uma representando um terço do total. A primeira parte é considerada como o núcleo, que seria formado por poucos periódicos. Já a zona intermediária seria formada por um volume um pouco maior de periódicos, enquanto a terceira parte é formada pela grande massa restante. A Lei de Bradford foi desenvolvida por uma pesquisa em cerca de 300 periódicos da área de geofísica, e descobriu que em apenas nove deles estavam concentrados cerca de 420 artigos. Enquanto isso, outros 58 publicaram apenas 404 artigos. Mesmo com uma limitação de análise estatística, essa lei deve ser considerada e utilizada como guia em pesquisas deste tipo.

III. Lei de Zipf: essa lei apresenta a correlação entre o número de palavras de um texto determinado com a frequência dessas mesmas palavras. Zipf (1949) verificou uma forte relação entre o número de palavras diferentes e a frequência com que ela é utilizada por meio da pesquisa. 


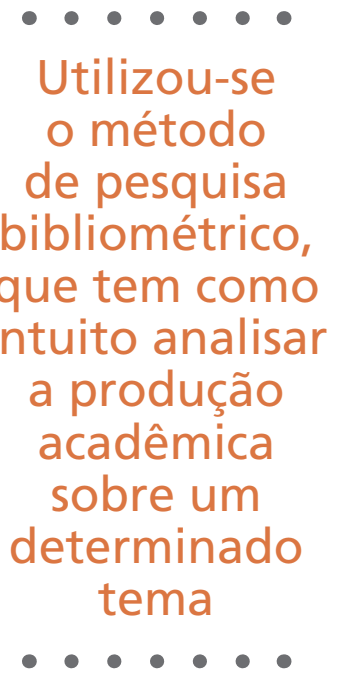

$\bullet \cdot \bullet \cdot \cdot 0$

Utilizou-se

de pesquisa

bibliométrico,

que tem como

intuito analisar

a produção

acadêmica

sobre um

tema
Outras categorias estabelecem somente uma contagem, como no caso da procedência geográfica e institucional e do levantamento da literatura mais influente de uma área, idade média da literatura utilizada e obsolescência da literatura. Essas categorias e outras, do mesmo tipo, podem se prestar a uma utilidade para a qual não foram criadas e para a qual não são destinadas, com base na perspectiva da Ciência da Informação (TEIXEIRA; IWAMOTO; MEDEIROS, 2013).

No que se refere à área da Administração, o trabalho realizado por Bertero, Caldas e Wood Junior (1999) analisou a produção científica no campo das Ciências Administrativas no Brasil. Os autores demonstraram que houve um significativo crescimento em número de artigos publicados em periódicos e eventos nacionais. Entretanto, no mesmo estudo, os autores mencionam que isso não refletiu em uma melhora na qualidade da pesquisa nessa área do conhecimento. Analisando a pesquisa científica em Administração no país, os autores encontraram evidências de que os estudos no campo apresentavam graves falhas epistemológicas, além de metodologias inadequadas, reflexões pouco originais e baixa aplicação prática (BERTERO; CALDAS; WOOD JUNIOR, 1999).

\section{Procedimentos metodológicos}

Os procedimentos metodológicos são detalhados aqui a partir dos principais elementos que constituem o delineamento da pesquisa. $\mathrm{O}$ delineamento contempla: estratégia de pesquisa, definições, população e amostra, coleta e tratamento dos dados (BABBIE, 1998; KERLINGER, 1996). Este estudo foi desenvolvido utilizando abordagem quantitativa e qualitativa, sendo caracterizado como exploratório-descritivo, com abordagens qualitativas no intuito de proporcionar melhor compreensão da problemática proposta e de obter maiores informações e inferências acerca do tema estudado (CRESWELL, 2010).

Além disso, utilizou-se o método de pesquisa bibliométrico, que tem como intuito analisar a produção acadêmica sobre um determinado tema. A pesquisa foi classificada quanto ao seu objetivo como descritiva, pois pretende-se observar, registrar, analisar e correlacionar fatos ou fenômenos (variáveis) sem manipulá-los (CERVO; BERVIAN, 2002). O método empregado na pesquisa utiliza técnicas de análise bibliométrica (BALESTRIN; VERSCHOORE; REYES JUNIOR, 2010; NASCIMENTO; JUNQUEIRA; MARTINS, 2010) que se destinam a quantificar e analisar a produção científica.

O desenvolvimento de uma pesquisa bibliométrica é composto por quatro etapas, a serem desenvolvidas adicionalmente à etapa de elaboração do problema de pesquisa. Primeiramente, deve-se escolher qual o foco da 
literatura que será analisada. Após isso, deve-se avaliar os dados coletados, para depois proceder a análise e interpretação dos dados coletados. Por fim, procede-se à apresentação e discussão dos resultados (COOPER; LINDSAY, 1998).

De forma geral, infere-se que a pesquisa bibliométrica tem como finalidade mensurar, de forma quantitativa, publicações científicas em periódicos (PRITCHARD, 1998), além de auxiliar o entendimento das relações entre os pesquisadores de uma determinada área (GUARIDO FILHO; MACHADO-DA-SILVA; GONÇALVES, 2010).

De acordo com Singleton e Straits (1999), a escolha da literatura que será analisada é um dos elementos essenciais nesse tipo de pesquisa, pois define qual será o escopo do estudo e pode impactar sua validade. Dessa forma, esta pesquisa foi desenvolvida pela consulta aos anais do Encontro Anual da ANPAD (Enanpad). A área abordada como objeto de estudo se deu por coincidir com o interesse desta pesquisa com a descrição da área temática do evento.

Para selecionar os artigos, foi feita uma consulta aos anais do Enanpad dentro da área de Ensino e Pesquisa em Administração e Contabilidade desde 1997. Porém, a área estudada aparece somente a partir do ano de 2001. Os artigos que foram objeto da presente análise foram obtidos por meio de um recorte longitudinal em um período de 14 anos, o que resultou em um total de 881 trabalhos que constam na amostra, tendo como critério de escolha os artigos apresentados na divisão acadêmica.

O tratamento dos dados foi elaborado de forma que possibilitasse a criação das listas de frequência e as matrizes de relacionamentos. Para a análise dos dados do evento, foram observados: a data de publicação dos estudos, os temas de interesse e a evolução ao longo dos anos de realização. Para melhor demonstrar a evolução da área e seus subtemas, optou-se por analisar os resultados em forma de percentuais, comparando os que apresentam maior relevância com o total de artigos no mesmo ano. Para efeito de facilitar a visualização dos dados, os temas de interesse estão listados no Quadro 1 e na discussão dos dados foi utilizada somente a numeração do tema: 
Quadro 1 - Temas de interesse da área de EPQ do Enanpad

\begin{tabular}{|c|c|}
\hline Tema 1 & Epistemologia \\
\hline Tema 2 & Estratégias e Métodos de Pesquisa \\
\hline Tema 3 & Conduta Ética e Responsável no Ensino e na Pesquisa \\
\hline Tema 4 & Aprendizanão do Professor e do Pesquisador \\
\hline Tema 5 & Ação Docente e Ambiente de Aprendizagem \\
\hline Tema 6 & Planejamento e Organização de Cursos e Programas \\
\hline Tema 7 & O Contexto Institucional do Ensino e da Pesquisa \\
\hline Tema 8 & Estudos Históricos, Reflexivos ou Críticos \\
\hline Tema 9 & Casos para Ensino \\
\hline Tema 10 & Educação para a Sustentabilidade \\
\hline Tema 11 & Fach \\
\hline
\end{tabular}

Fonte: Associação Nacional dos Programas de Pós-graduação em Administração (2015).

A catalogação dos trabalhos apresentados foi elaborada, primeiramente, utilizando o software Mendeley Desktop, com o intuito de organizar os arquivos constantes nos anais do evento. Após essa etapa, utilizou-se o software Microsoft Excel, para tabulação e criação das tabelas e gráficos que constam na análise do trabalho. Por fim, foi utilizada a estatística descritiva para poder subsidiar a análise dos dados.

\section{Análise e discussão dos resultados}

Do total de 881 artigos publicados que foram analisados, apresentados na Tabela 1, observa-se que na área de EPQ houve aumento na quantidade de trabalhos apresentados entre 2001 e 2014. Vale ressaltar que, de forma proporcional, os trabalhos da área apresentam pouca representatividade no total do evento, tendo em vista que a maioria dos trabalhos estão na área de Estudos Organizacionais (EOR) e Estratégias Organizacionais (ESO).

\section{Tabela 1 - Artigos publicados por ano}

\begin{tabular}{c|c|c|c}
\hline Ano & $\begin{array}{c}\text { Número de Artigos } \\
\text { Publicados }\end{array}$ & Ano & $\begin{array}{c}\text { Número de Artigos } \\
\text { Publicados }\end{array}$ \\
\hline 2001 & 24 & 2008 & 100 \\
\hline 2002 & 28 & 2009 & 72 \\
\hline 2003 & 37 & 2010 & 74 \\
\hline 2004 & 48 & 2011 & 64 \\
\hline 2005 & 49 & 2012 & 73 \\
\hline 2006 & 62 & 2013 & 91 \\
\hline 2007 & 92 & 2014 & 67 \\
\hline Total & & $\mathbf{8 8 1}$ \\
\hline
\end{tabular}

Fonte: Elaborado pelos autores.

B. Téc. Senac, Rio de Janeiro, v. 43, n. 1, p. 182-197, jan./abr. 2017. 
Já no Gráfico 1, está demonstrada a evolução quantitativa dos trabalhos publicados na área de EPQ. Percebe-se que há forte tendência de crescimento da quantidade de trabalhos apresentados, sobretudo entre os anos de 2001 e 2008, quando houve um salto de 24 para 100 trabalhos. Entretanto, é importante frisar que os anos de 2007 e 2008 foram atípicos, pois apresentam uma elevação acentuada da curva de crescimento de trabalhos apresentados (por motivos, até então, desconhecidos). Nos anos subsequentes (2009 a 2014), ocorreu uma estabilização perto da média de trabalhos da área que é de, aproximadamente, 62 trabalhos/ano. Vale ressaltar que, ao se fazer o levantamento dos artigos, não se considerou a viabilidade do tema nem algo relacionado com sua escolha ou métodos adotados, pois o foco do estudo consiste em analisar somente a evolução dos estudos na área de EPQ.

\section{Gráfico 1- Evolução das publicações na área de EPQ do Enanpad}

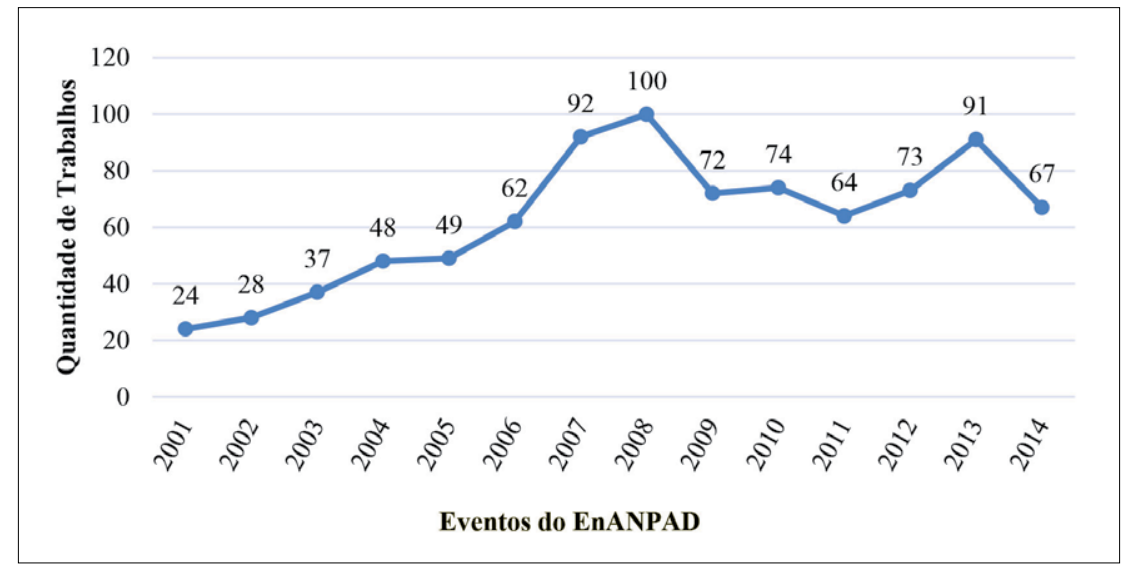

Fonte: Elaborado pelos autores.

No que se refere aos temas de interesse específicos da área, analisou-se também qual foi a evolução individual de cada um dos 11 temas propostos pelo evento. É importante esse tipo de análise, pois observando cada uma dessas temáticas é possível encontrar fatores que podem ser determinantes para continuidade das pesquisas e do tema no escopo da área de EPQ. Isso pode proporcionar um direcionamento para pesquisadores, principalmente, para aqueles que são iniciantes, influenciando o crescimento e a disseminação de futuras pesquisas (SOUZA; RIBEIRO, 2013). 
Ao se analisar o Gráfico 2, um índice que chama a atenção é em relação ao Tema 11, "Educação para Sustentabilidade", que apresenta o menor índice de trabalhos apresentados ao longo dos anos (0,57\% ou 5 de 881). Isso pode ocorrer por três motivos: 1 ) desinteresse dos pesquisadores da área; 2) baixa qualidade dos trabalhos submetidos e, consequentemente, pouquíssimas aprovações para apresentação e 3) por tratar-se de uma temática contemporânea abrangida em trabalhos submetidos a outras áreas.

No Gráfico 2, também se pode observar que os temas dominantes na área são os que tratam da "Aprendizagem e Formação Acadêmica" (Tema 5), com 20,89\% dos trabalhos da área e "Casos para Ensino" (Tema 10) com 17,03\%. Esse predomínio pode ser exercido devido ao Tema 5 ser foco de debates e pesquisas no meio acadêmico, buscando entender como ocorrem os fenômenos na área de Administração. Além disso, o Tema 10 se refere diretamente a uma ferramenta de ensino-aprendizagem que despertou o interesse dos docentes na área, sobretudo a partir de meados da primeira década dos anos 2000.

\section{Gráfico 2 - Participação das temáticas na área de EPQ do Enanpad}

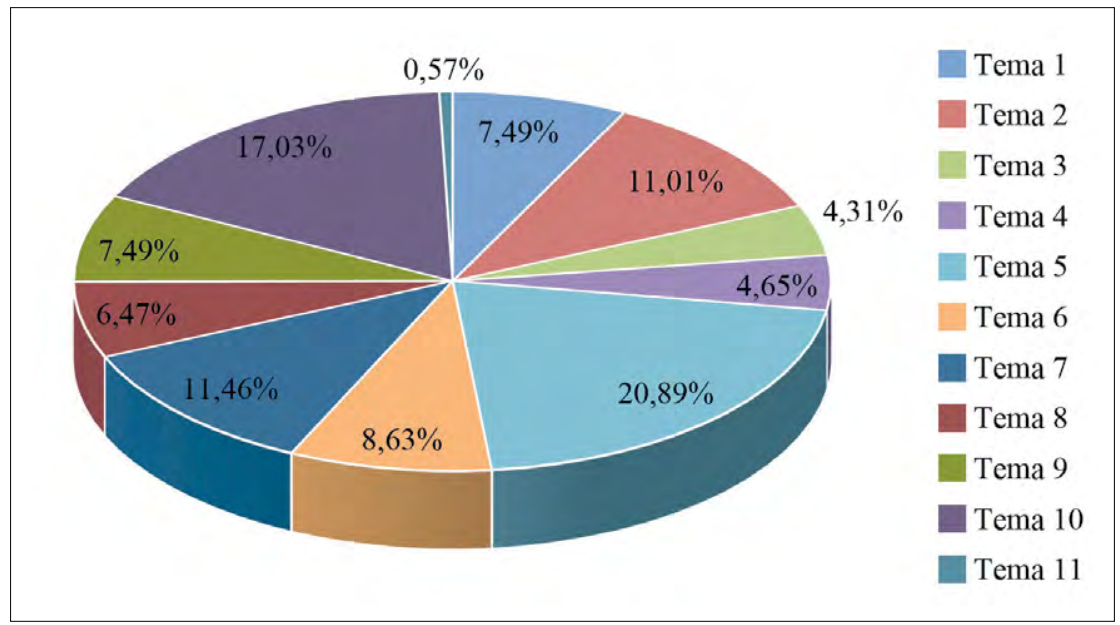

Fonte: Elaborado pelos autores.

Os dados a seguir mostram a evolução em valores percentuais dos trabalhos publicados em cada área temática entre os anos de 2001 e 2014. Na Tabela 2, está descrito como cada área temática evoluiu percentualmente em relação ao total dos 881 artigos apresentados: 


\section{Tabela 2 - Percentual de artigos publicados de cada área temática por ano}

\begin{tabular}{c|c|c|c|c|c|c|c|c|c|c|c|c|c|c}
\hline Tema 1 & $0,00 \%$ & $7,14 \%$ & $8,11 \%$ & $6,25 \%$ & $8,16 \%$ & $8,06 \%$ & $4,35 \%$ & $4,00 \%$ & $11,11 \%$ & $18,92 \%$ & $12,50 \%$ & $6,85 \%$ & $6,59 \%$ & $0,00 \%$ \\
\hline Tema 2 & $20,83 \%$ & $7,14 \%$ & $16,22 \%$ & $8,33 \%$ & $10,20 \%$ & $17,74 \%$ & $9,78 \%$ & $12,00 \%$ & $8,33 \%$ & $12,16 \%$ & $12,50 \%$ & $6,85 \%$ & $10,99 \%$ & $7,46 \%$ \\
\hline Tema 3 & $4,17 \%$ & $7,14 \%$ & $2,70 \%$ & $4,17 \%$ & $4,08 \%$ & $4,84 \%$ & $6,52 \%$ & $6,00 \%$ & $4,17 \%$ & $2,70 \%$ & $7,81 \%$ & $0,00 \%$ & $2,20 \%$ & $4,48 \%$ \\
\hline Tema 4 & $4,17 \%$ & $7,14 \%$ & $5,41 \%$ & $12,50 \%$ & $6,12 \%$ & $6,45 \%$ & $1,09 \%$ & $4,00 \%$ & $2,78 \%$ & $6,76 \%$ & $4,69 \%$ & $4,11 \%$ & $0,00 \%$ & $7,46 \%$ \\
\hline Tema 5 & $33,33 \%$ & $35,71 \%$ & $40,54 \%$ & $25,00 \%$ & $24,49 \%$ & $20,97 \%$ & $17,39 \%$ & $11,00 \%$ & $18,06 \%$ & $13,51 \%$ & $15,63 \%$ & $28,77 \%$ & $19,78 \%$ & $22,39 \%$ \\
\hline Tema 6 & $12,50 \%$ & $3,57 \%$ & $8,11 \%$ & $8,33 \%$ & $8,16 \%$ & $12,90 \%$ & $4,35 \%$ & $14,00 \%$ & $1,39 \%$ & $5,41 \%$ & $4,69 \%$ & $0,00 \%$ & $23,08 \%$ & $8,96 \%$ \\
\hline Tema 7 & $4,17 \%$ & $3,57 \%$ & $8,11 \%$ & $18,75 \%$ & $18,37 \%$ & $12,90 \%$ & $14,13 \%$ & $10,00 \%$ & $18,06 \%$ & $4,05 \%$ & $15,63 \%$ & $8,22 \%$ & $10,99 \%$ & $7,46 \%$ \\
\hline Tema 8 & $0,00 \%$ & $0,00 \%$ & $0,00 \%$ & $4,17 \%$ & $0,00 \%$ & $9,68 \%$ & $3,26 \%$ & $5,00 \%$ & $18,06 \%$ & $12,16 \%$ & $6,25 \%$ & $10,96 \%$ & $4,40 \%$ & $4,48 \%$ \\
\hline Tema 9 & $16,67 \%$ & $17,86 \%$ & $8,11 \%$ & $4,17 \%$ & $16,33 \%$ & $3,23 \%$ & $8,70 \%$ & $14,00 \%$ & $1,39 \%$ & $1,35 \%$ & $7,81 \%$ & $5,48 \%$ & $4,40 \%$ & $7,46 \%$ \\
\hline Tema 10 & $0,00 \%$ & $10,71 \%$ & $2,70 \%$ & $6,25 \%$ & $4,08 \%$ & $1,61 \%$ & $30,43 \%$ & $19,00 \%$ & $15,28 \%$ & $22,97 \%$ & $12,50 \%$ & $28,77 \%$ & $17,58 \%$ & $29,85 \%$ \\
\hline Tema 11 & $4,17 \%$ & $0,00 \%$ & $0,00 \%$ & $2,08 \%$ & $0,00 \%$ & $1,61 \%$ & $0,00 \%$ & $1,00 \%$ & $1,39 \%$ & $0,00 \%$ & $0,00 \%$ & $0,00 \%$ & $0,00 \%$ & $0,00 \%$ \\
\hline Total & $100 \%$ & $100 \%$ & $100 \%$ & $100 \%$ & $100 \%$ & $100 \%$ & $100 \%$ & $100 \%$ & $100 \%$ & $100 \%$ & $100 \%$ & $100 \%$ & $100 \%$ & $100 \%$ \\
\hline
\end{tabular}

Fonte: Elaborada pelos autores.

No Gráfico 3, percebem-se algumas questões interessantes. Primeiramente, em relação ao Tema 5, "Aprendizagem e Formação Acadêmica", que apesar do número absoluto de trabalhos não ter grande variação, nota-se como sua participação no volume de trabalhos caiu substancialmente depois de 2003. Muito disso se deve ao crescimento de trabalhos apresentados no Tema 7, "Planejamento e Organização de Cursos e Programas", que teve um crescimento de 2002 para 2003, o que contribuiu para o início do declínio de participação do Tema 5.

Ocorre que o tema que apresenta uma tendência de crescimento, ao longo dos eventos, é o Tema 10, "Casos para Ensino". Esse crescimento pode ser justificado levando em consideração o aumento do interesse por parte de docentes e discentes de cursos de Administração por técnicas alternativas de ensino. Dessa forma, leva a uma preocupação dos pesquisadores, por desenvolverem casos de estudo para serem utilizados em sala de aula e enviá-los para o evento, no intuito de, com o debate e discussão, desenvolver o trabalho no sentido de viabilizar material a ser utilizado em sala de aula. 


\section{Gráfico 3 - Evolução das temáticas na área de EPQ do Enanpad}

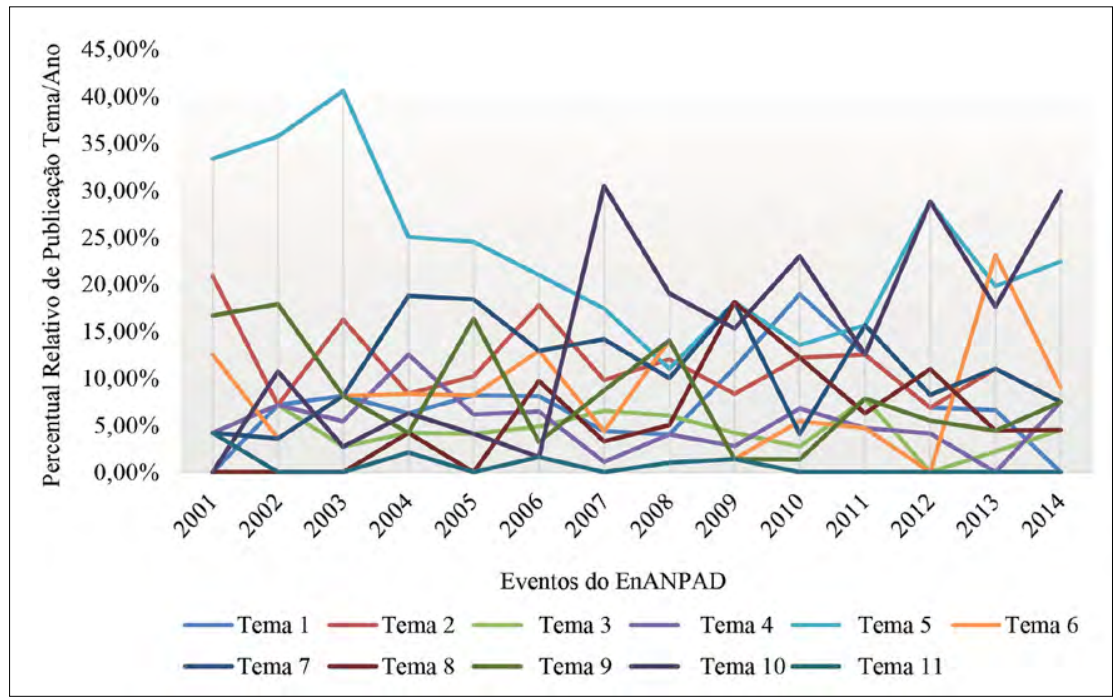

Fonte: Elaborado pelos autores.

O que chama a atenção nos dados de evolução dos trabalhos apresentados é a tendência estagnada em participação percentual e números absolutos de trabalhos no Tema 1, "Epistemologia". Tendo em vista a preocupação latente na área de Administração com a qualidade dos trabalhos que são produzidos e também as questões relativas à coerência nas pesquisas da área, pode causar estranhamento o fato de que discussões epistemológicas gerais na área não tenham destaque. Muitos defendem que a Administração seria um ramo da ciência que não possui seus próprios métodos e técnicas de investigação e se utiliza de metodologias de outras ciências (BUNGE, 1980), nesse sentido, as discussões sobre a cientificidade da área deveriam ter mais espaço no maior evento nacional da área.

\section{Considerações finais}

Este estudo teve por objetivo descrever o perfil das pesquisas e a evolução da área de Ensino e Pesquisa em Administração e Contabilidade (EPQ) nos artigos publicados nos Anais do Encontro Anual da Associação Nacional dos Programas de Pós-graduação em Administração (Enanpad) no período de 2001-2014. Os temas que se destacaram nesta análise foram o de "Casos para Ensino" e "Aprendizagem e Formação Acadêmica", que representam a maior parcela percentual dos trabalhos publicados na área.

Entretanto, os resultados apontam que a área ainda não atingiu maturidade em suas publicações e precisa percorrer um longo caminho para sua con- 
solidação. Mesmo que o número de artigos mostre uma tendência de crescimento e apresente algumas características que favorecem a qualidade da pesquisa, no contexto do Enanpad ainda falta muito para atingir o volume de trabalhos de outras áreas, como Estudos Organizacionais (EOR) e Estratégias Organizacionais (ESO).

Constatou-se que a maioria dos artigos investigados aborda temas relativos ao ensino e à aprendizagem em Administração e Contabilidade, tendo forte tendência a trabalhar com os "Casos de Ensino", que vêm ganhando importância e espaço no ambiente universitário, o que mostra uma tendência de crescimento dessa abordagem. Além disso, os trabalhos que tratam da "Aprendizagem e Formação Acadêmica" se mantêm constantes no que se refere à sua participação em trabalhos apresentados no evento e se apresentam como uma constante dentro da área.

Academicamente, os dados evidenciam que essa área ainda é marginal, quando comparada com outras áreas no evento, uma vez que deveria receber maior atenção e propiciar estudos mais consistentes no que se refere aos caminhos epistemológicos e metodológicos que são utilizados nas pesquisas organizacionais. Dessa forma, seria possível que os trabalhos empíricos pudessem ter melhor desenho metodológico, possibilitando caminhar em direção à construção de conhecimento científico mais consistente.

É evidente que não se pode considerar a Administração uma ciência básica, dado que se utiliza de técnicas metodológicas e epistemologias de outras ciências, tais como Economia, Sociologia, Psicologia, entre outras. Entretanto, vale a ressalva de que a multidisciplinaridade é uma atividade essencial para o desenvolvimento científico, ou seja, não se deve pensar em atividade de pesquisa científica sem levar essa premissa em consideração.

Como limitação do estudo, vale ressaltar que a amostra de trabalhos ficou restrita aos anais do evento e que publicações em periódicos nacionais e internacionais, bem como teses e dissertações, não foram levadas em consideração. Sugere-se, então, que estudos futuros se voltem para a análise dos conteúdos utilizados na fundamentação teórica, bem como na análise de trabalhos oriundos de outras fontes e no estudo das redes de pesquisadores e instituições.

Além disso, seria oportuno um estudo mais aprofundado dos trabalhos que tratam da temática analisada em periódicos. Na área de Administração, Ciências Contábeis e Turismo, de acordo com Souza e Ribeiro (2013), foram registrados 837 periódicos classificados pelo Qualis da Capes em 2011, como sendo de A1 a C, tanto nacionais quanto internacionais. Dessa forma, seria importante uma análise mais profunda a ser realizada nos principais periódicos constantes no Qualis da área de Administração. 


\section{Referências}

ASSOCIAÇÃO NACIONAL DOS PROGRAMAS DE PÓS-GRADUAÇÃO EM ADMINISTRAÇÃO. Divisão de Ensino e Pesquisa em Administração e Contabilidade (EPQ) no Enanpad. Rio de Janeiro, [2015?]. Disponível em <http:// www.anpad.org.br>. Acesso em: 25 jul. 2015.

BABBIE, E. R. The practice of social research. 8th. ed. Belmont: Wadsworth Publ., 1998.

BALESTRIN, A.; VERSCHOORE, J. R.; REYES JUNIOR, E. O campo de estudo sobre redes de cooperação interorganizacional no Brasil. Revista de Administração Contemporânea, Rio de Janeiro, v. 14, n. 3, p. 458-477, 2010. Disponível em: <http://www.scielo.br/pdf/rac/v14n3/v14n3a05.pdf>. Acesso em: 30 jul. 2015.

BERTERO, C. O.; CALDAS, M. P.; WOOD JUNIOR, T. Produção científica em administração de empresas: provocações, insinuações e contribuições para um debate local. Revista de Administração Contemporânea, Rio de Janeiro, v. 3, n. 1, p. 147-178, 1999. Disponível em: <http://www.anpad.org.br/periodicos/content/frame_base. php?revista=1>. Acesso em: 15 jul. 2015.

BRADFORD, S. C. Sources of information on specific subjects. Engineering, v. 137, n.1, p. 85-86, 1934.

BRAGA, G. Relações bibliométricas entre a frente de pesquisa (research front) e revisões da literatura: estudo aplicado à ciência da informação. Ciência da Informação, Brasília, DF, v. 2, n. I, p. 9-26, 1973.

BUNGE, M. Ciência e desenvolvimento. Belo Horizonte: Itatiaia; São Paulo: EdUSP, 1980.

CERVO, A. L.; BERVIAN, P. A. Metodologia científica. 5. ed. São Paulo: Makron Books, 2002.

COOPER, H. M.; LINDSAY, J. J. Research synthesis and meta-analysis. In: BICKMAN, L.; ROG, D. J. (Ed.). Handbook of applied social research methods. Thousand Oaks: Sage Publ., 1998. p. 315-342.

CRESWELL, J. W. Projeto de pesquisa: métodos qualitativo, quantitativo e misto. Porto Alegre: Artmed, 2010.

FONSECA, Edson Nery da (Org.). Bibliometria: teoria e prática. São Paulo: Cultrix: EdUSP, 1986.

GALLON, A. V. et al. Um estudo longitudinal da produção científica em administração direcionada à temática ambiental. Revista Alcance, Biguaçu, v. 15, n. 1, p. 81-101, 2008.

GUARIDO FILHO, E. R.; MACHADO-DA-SILVA, C. L.; GONÇALVES, S. A. Organizational institutionalism in the academic field in Brazil: social dynamics and networks. Revista de Administração Contemporânea, Rio de Janeiro, n. 14, p. 149-172, 2010. Edição 
especial. Disponível em: <http://www.anpad.org.br/periodicos/content/frame_base. php?revista=1>. Acesso em: 23 set. 2015.

HID, D. S.; NASCIMENTO, C.; OLIVEIRA, D. A. Análise das publicações internacionais relacionadas ao desenvolvimento sustentável na área de administração: uma análise bibliométrica da produção científica. Administração: ensino e pesquisa, Rio de Janeiro, v. 13, n. 4, p. 653-671, 2012.

KERLINGER, F. N. Metodologia da pesquisa em ciências sociais: um tratamento conceitual. São Paulo: EPU, 1996.

LOTKA, A. J. The frequency distribution of scientific productivity. Journal of the Washington Academy of Sciences, v. 16, n. 12, p. 317-323, 1926.

MACHADO-DA-SILVA, C. L.; CUNHA, V. C.; AMBONI, N. Organizações: o estado da arte da produção acadêmica no Brasil. In: ENCONTRO NACIONAL DOS PROGRAMAS DE PÓS-GRADUAÇÃO EM ADMINISTRAÇÃO, 14., 1990, Florianópolis. Anais... Rio de Janeiro: Anpad, 1990.

MACIAS-CHAPULA, C. A. 0 papel da informetria e da cienciometria e sua perspectiva nacional e international. Ciência da Informação, Brasília, DF, v. 27, n. 2, p. 134140, 1998.

NASCIMENTO, A. R. do; JUNQUEIRA, E.; MARTINS, G. de A. Pesquisa acadêmica em contabilidade gerencial no Brasil: análise e reflexões sobre teorias, metodologias e paradigmas. Revista de Administração Contemporânea, Rio de Janeiro, v. 14, n. 6, p. 1113-1133, nov./dez. 2010. Disponível em: <http://www.anpad.org.br/ periodicos/content/frame_base.php?revista=1>. Acesso em: 24 set. 2015.

PRITCHARD, A. Statistical bibliography or bibliometrics? Journal of Documentation, v. 25, n. 4, p. 344-349, 1969.

PRITCHARD, C. Trends in economic evaluation. London: Office of Health Economics, Apr. 1998. (OHE briefing, n. 36).

ROSSONI, L. et al. Estratégia em organizações: a produção científica em eventos nacionais entre 2001 e 2006. In: ENCONTRO DE ESTUDOS EM ESTRATÉGIA: 3 E's, 1., 2007, São Paulo. Anais... São Paulo: Anpad, 2007.

SINGLETON, R. A.; STRAITS, B. C. Approaches to social research. New York: Oxford University Press, 1999.

SOUZA, M. T. S.; RIBEIRO, H. C. M. Sustentabilidade ambiental: uma meta-análise da produção brasileira em periódicos de administração. Revista de Administração

Contemporânea, Rio de Janeiro, v. 17, n. 3, p. 368-396, 2013. Disponível em: <http:// www.scielo.br/scielo.php?script=sci_arttext\&pid=\$1415-65552013000300007>. Acesso em: 25 set. 2015. 
TEIXEIRA, M. L. M.; IWAMOTO, H. M.; MEDEIROS, A. L. Estudos bibliométricos (?) em administração: discutindo a transposição de finalidade. Administração: ensino e pesquisa, Rio de Janeiro, v. 14, n. 3, p. 423-452, 2013. Disponível em: <http://www. spell.org.br/documentos/ver/31506/estudos-bibliometricos-----em-administracao-di--->. Acesso em: 20 set. 2015.

VANTI, N. A. P. Da bibliometria à webometria: uma exploração conceitual dos mecanismos utilizados para medir o registro da informação e a difusão do conhecimento. Ciência da Informação, Brasília, DF, v. 31, n. 2, p. 152-162, 2002.

ZIPF, G. K. Human behavior and the principle of least effort. Cambridge: Addison Wesley, 1949.

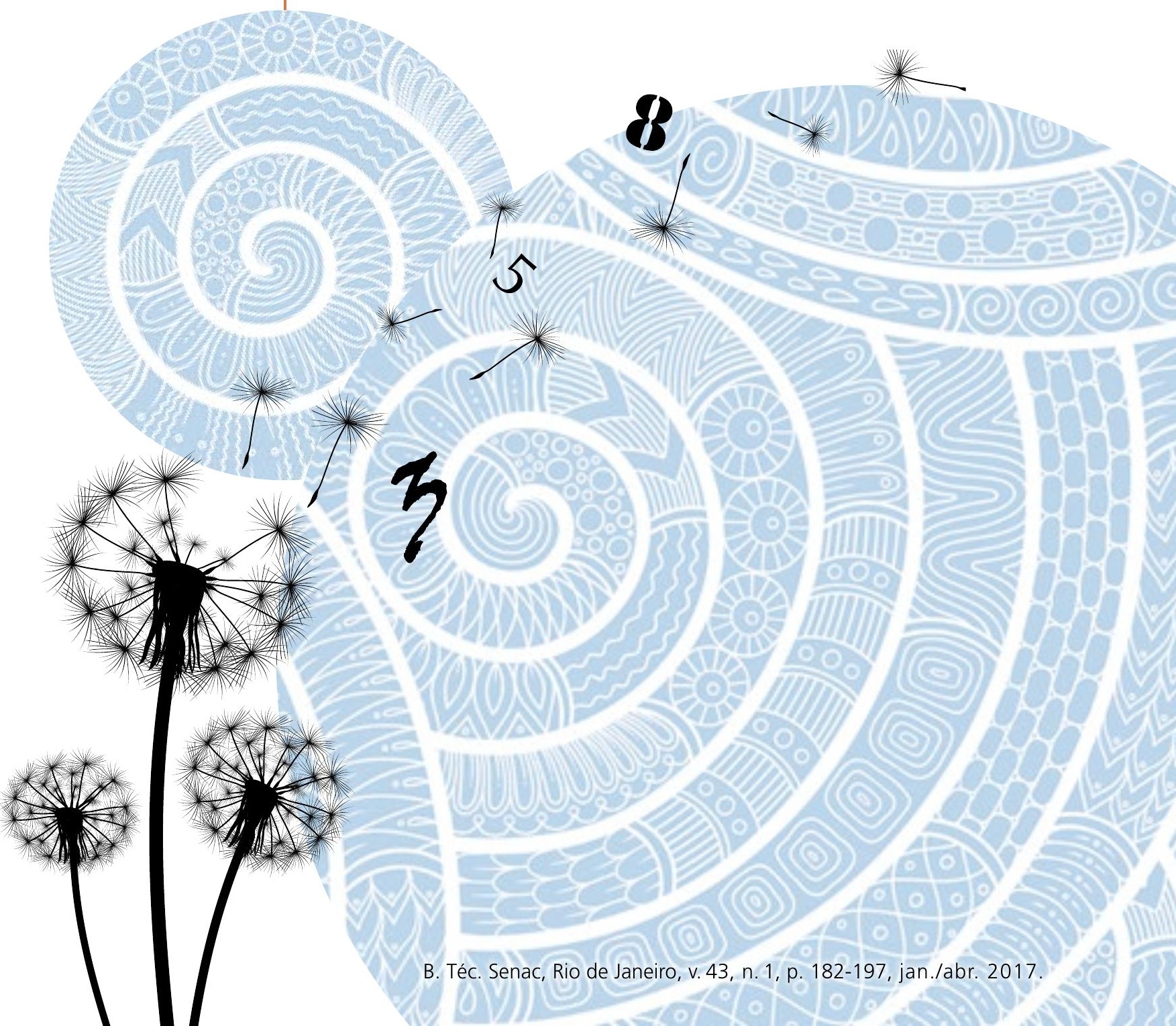

